\title{
Penerapan Karakteristik Milenial sebagai Work-Life-Balance dalam Perancangan Fasilitas dan Elemen Interior Point Lab Co-Working Space
}

\author{
Adhiestyaputri Kintari ${ }^{1}$, Mahendra Nur Hadiansyah ${ }^{2}$, Widyanesti Liritantri ${ }^{3}$ \\ 1,2,3 Program Studi Desain Interior, Universitas Telkom Bandung, Jawa Barat, Indonesia \\ adhiestyaputrik@gmail.com ${ }^{1}$, mahendrainterior@telkomuniversity.ac.id ${ }^{2}$,widyanesti@telkomuniversity.ac.id ${ }^{3}$
}

\begin{abstract}
ABSTRAK
Point Lab Co-Working Space dibangun oleh PT. Pos Properti Indonesia yang bertujuan sebagai ruang bekerja bersama bagi para pelaku bisnis baik pekerja lepas ataupun perusahaan startup untuk membesarkan usahanya. Sasaran pengguna utama Point Lab merupakan generasi milenial yang juga masuk dalam usia produktif tahun bonus demografi Indonesia. Berdasarkan karakteristiknya, generasi milenial yang hidup bersamaan dengan perkembangan industri teknologi digital, mereka akrab menggunakan teknologi dan dapat menjadi lebih antusias dan produktif baik dalam kehidupan pekerjaan atau sosialnya. Termasuk co-worker di Point Lab yang di dominasi pengguna yang bekerja di bidang digital seperti digital marketing, digital advertising, desain grafis, dan e-commerce. Selain untuk tempat bekerja, sebuah co-working space merupakan lingkungan kerja yang memiliki peluang besar bagi penggunanya untuk memperluas relasi dan hubungan kerja sama. Hubungan kerja sama atau kolaborasi ini akan tercipta jika sering terjadi komunikasi dan interaksi sosial antar pengguna dalam co-working space. Dalam upaya mencapai tujuan Point Lab dan para tenant, Point Lab dituntut untuk menerapkan fasilitas dan elemen interior yang dapat memberikan dampak psikologi ruang yang dapat mendukung antusiasme dan produktivitas penggunanya dalam bekerja maupun menyeimbangkan kebutuhan kehidupan sosialnya.
\end{abstract}

Kata kunci: Ruang Kerja Bersama; Startup Digital Milenial; Bekerja dan Interaksi Sosial

\section{ABSTRACT}

Point Lab Co-Working Space was built by PT. Pos Properti Indonesia which aims as a space to work together for business people both freelancers or startup companies to grow their businesses. The main target users of Point Lab are millennials who are also in the productive age of the Indonesian demographic bonus year. Based on its characteristics, millennial generation who live together with the development of the digital technology industry, they are familiar with using technology and can be more enthusiastic and productive in their work or social life. Including co-workers at Point Lab dominated by users who work in digital jobs such as digital marketing, digital advertising, graphic design, and ecommerce. In addition to the workplace, a co-working space is a work environment that has a great opportunity for users to expand relations and cooperation. This collaboration relationship will be created if there is frequent communication and social interaction between users in a co-working space. In an effort to achieve the goals of Point Lab and its tenants, Point Lab is required to implement facilities and interior elements that can have a psychological impact on space that can support the enthusiasm and productivity of users in working and balancing the needs of social life.

Keyword: Coworking Space; Millennials Digital Startup; Work and Social Interaction

\section{PENDAHULUAN}

Bisnis properti co-working space yang di kelola oleh PT. Pos Properti Indonesia ini didirikan pada tanggal 10 Mei 2018. Sasaran pengguna utamanya ditujukan untuk startup atau pelaku bisnis dari generasi milenial dengan tujuan para tenant dapat mengembangkan bisnisnya dan Point Lab juga dapat berkontribusi bagi perkembangan PT. Pos Properti dan PT. Pos Indonesia. Menurut data yang ditulis dalam Buku Statistik Gender Tematik Profil Generasi Milenial Indonesia (2018), generasi milenial menyukai suasana ruang kerja yang fleksibel, nyaman, transparan, dan fasilitas lengkap yang dapat mendukung pekerjaan mereka. Milenial 
juga memiliki karakter yang mementingkan Work-Life-Balance. Keseimbangan antara pekerjaan dan sosial ini penting dalam co-working space, menurut Mathias Schuermann (2014) co-working space merupakan "more than a place to work" yang berarti lebih dari tempat untuk bekerja. Dengan kata lain, para pengguna co-working space memiliki peluang yang besar untuk memperluas relasi dan hubungan kerja sama yang berawal dari sering terjadinya komunikasi dan interaksi sosial antar penggunanya, kemudian saling berdiskusi, bertukar pikiran hingga berkolaborasi dan menciptakan inovasi baru. Makna dari co-working space akan hilang, bila hal tersebut tidak terdapat di Point Lab Co-Working Space. Karena fungsi dari co-working space sebenarnya yaitu merekatkan para pengguna menjadi sebuah komunitas.

Eksisting Point Lab Co-Working Space berada di lokasi yang cukup strategis ditengah kota Bandung yang dikelilingi bangunan komersil hal ini sangat berpotensi baik bagi Point Lab untuk menarik para pelaku bisnis lainnya. Sementara itu co-worker di Point Lab Co-Working Space sebagian besarnya merupakan startup digital, yaitu digital marketing, advertising, $e$ commerce dan desain grafis. Fasilitas Point Lab yang tersedia saat ini adalah private office, function room, shared area atau ruang kerja kolektif dan area istirahat. Berdasarkan hasil analisis dari 3 (tiga) studi banding dan literatur, Di area istirahat tersebut seharusnya dapat menjadi titik temu para co-worker Point Lab sehingga dapat menjadi pusat ruang sosial di coworking space tersebut. Namun hal itu belum di manfaatkan oleh Point Lab. Selain itu terdapat ruang rapat yang menjadi syarat fasilitas di sebuah co-working space yang belum disediakan secara khusus di eksisting objek perancangan ini.

Berdasarkan fenomena dan analisis dari studi banding maupun standarisasi ideal dan fungsi co-working space, beserta karakteristik pengguna dan kondisi objektif Point Lab, untuk mengakomodasi kebutuhan co-worker Point Lab yang merupakan milenial terutama startup digital, diperlukan fasilitas dan elemen ruang yang dapat memberikan stimulasi untuk mendukung kinerja mereka dalam bekerja, selain itu juga untuk mendorong komunikasi atau interaksi sosial baik antar individu atau kelompok yang terdapat di Point Lab Co-Working Space sehingga dapat saling mengapresiasi, berbagi ide dan pengetahuan hingga bekerja sama atau berkolaborasi.

\section{METODE PENELITIAN}

Metode penelitian pada studi kasus ini menggunakan metode kualitatif dengan melakukan beberapa tahapan sebagai berikut:

\section{A. Pengumpulan Data Primer}

Pengumpulan data primer dengan melakukan pengamatan atau observasi langsung, dokumentasi dan wawancara terhadap objek Point Lab Co-Working Space dan studi banding yaitu Bandung Digital Valley, CoHive Co-Working Space Pos Indonesia Jakarta, GoWork CoWorking Space Menara Rajawali Jakarta. Menyebarkan kuesioner terkait kebutuhan fasilitas pengguna kepada co-worker di Point Lab Co-Working Space.

\section{B. Pengumpulan Data Sekunder}

Pengumpulan data sekunder dilakukan dengan mengumpulkan data literatur atau standarisasi yang diperoleh dari buku, jurnal ataupun web yang berkaitan dengan co-working space yang ideal dengan karakteristik pengguna dominan yaitu startup digital milenial.

\section{Analisis Data}

Analisis data dilakukan setelah proses pengumpulan data primer dan sekunder. Data yang didapat kemudian diolah dan dianalisis lebih lanjut dengan menggunakan tabel komparasi yang menghasilkan kesimpulan untuk diterapkan pada objek perancangan Point Lab Co-Working 
Space. Variabel yang digunakan adalah elemen interior yang terdapat di tiap jenis fasilitas ruang pada co-working space.

\section{HASIL PENELITIAN DAN PEMBAHASAN}

\section{A. Definisi dan Nilai sebuah Co-Working Space yang Ideal}

Menurut kamus oxford, co-working space adalah lingkungan kerja bersama atau kantor yang digunakan oleh orang-orang yang bekerja sendiri atau bekerja untuk perusahaan dan bidang yang berbeda. Seperti pengusaha, freelancer, konsultan, investor, artist, peneliti, mahasiswa, dan lainnya. Menurut (Stumpf, 2013) terdapat nilai-nilai pada sebuah co-working space, yaitu komunitas, aksesibilitas, kolaborasi, komunikasi, keterbukaan dan kreativitas. Berdasarkan pemahaman dari definisi dan nilai-nilai tersebut penerapan pendekatan desain yang digunakan adalah psikologi ruang, karena dengan pendekatan ini diharapkan dapat memberi pengaruh positif dan dapat membantu proses pencapaian "tujuan" dari pemilik ataupun user Point Lab Co-Working Space itu sendiri. Tujuan tersebut berkaitan dengan alasan para co-worker yang menyewa sebuah co-working space, selain membutuhkan ruang kerja yang praktis, fleksibel dengan fasilitas yang mendukung kinerja, mereka juga berharap memiliki banyak peluang untuk memperluas relasi hingga berkolaborasi antar co-worker yang dapat menciptakan ide atau inovasi baru sehingga mereka dapat mengembangkan bisnisnya. Kemudian fungsi dan syarat Point Lab sebagai co-working space yang ideal harus memiliki nilai komunitas dan kolaborasi didalamnya. Untuk itu, konsep perancangan To-Get-There ini memiliki tiga arti yang saling berhubungan, yaitu to gather (untuk berkumpul), together (bersama) dan to get there (untuk kesana, mencapai tujuan). Konsep ini bertujuan untuk mengarahkan para co-worker untuk mendukung nilai - nilai pada Co-Working Space.

\section{B. Penerapan Fasilitas Berdasarkan Aktivitas Pengguna}

Kegiatan yang dilakukan dalam co-working space memiliki pola kerja yang fleksibel dan dinamis. Untuk merespon perkembangan pola kerja tersebut dibuat klasifikasi aktivitas di dalam co-working space (Dugyu Ergin, 2013)

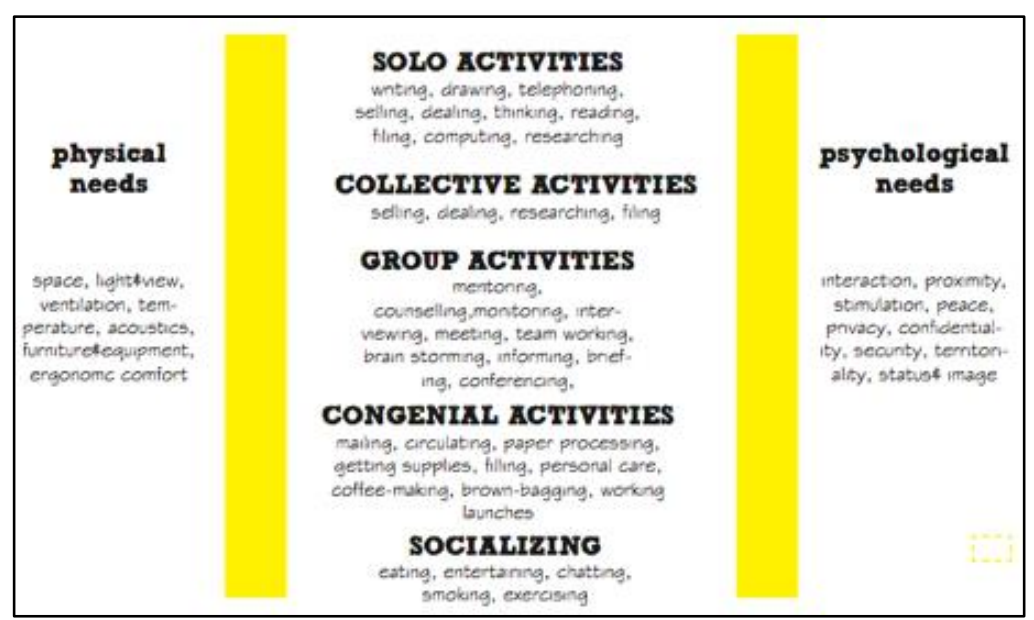

Gambar 1. Klasifikasi Aktivitas Pengguna Co-Working Space

Sumber: "How to Create a Co-Working Space Handbook” oleh Dugyu Ergin (2013)

Berdasarkan klasifikasi aktivitas tersebut, terdapat pembagian ruang dalam co-working space yang akan diterapkan dalam objek perancangan, berikut tabel penjelasannya: 
Tabel 1. Klasifikasi Aktivitas Pengguna Co-Working Space

\begin{tabular}{|c|c|c|}
\hline $\begin{array}{c}\text { Jenis } \\
\text { Fasilitas }\end{array}$ & Ruang & Kegiatan \\
\hline \multirow{8}{*}{ Workspace } & $\begin{array}{l}\text { Individual Workspace } \\
\text { (Workpods) }\end{array}$ & Bekerja individu \\
\hline & $\begin{array}{l}\text { Group Workspace } \\
\text { (Workpods) }\end{array}$ & Bekerja kelompok (saling kenal) \\
\hline & Collective Workspace & $\begin{array}{l}\text { Bekerja kolektif/ berbagi peralatan } \\
\text { dengan stranger }\end{array}$ \\
\hline & Quiet Area & Bekerja kolektif suasana minim suara \\
\hline & Lab Computer & Rendering, Visualisasi \\
\hline & Private Office & Bekerja tim (saling kenal) \\
\hline & Meeting Room & Diskusi, Briefing suasana formal \\
\hline & Informal Meeting Area & $\begin{array}{l}\text { Diskusi santai dengan konsep ruang } \\
\text { terbuka. }\end{array}$ \\
\hline \multirow{7}{*}{$\begin{array}{l}\text { Support } \\
\text { Space }\end{array}$} & Training Room & $\begin{array}{l}\text { Pelatihan, Sosialisasi atau workshop } \\
\text { untuk member }\end{array}$ \\
\hline & Auditorium & $\begin{array}{l}\text { Seminar atau workshop dengan jumlah } \\
\text { peserta besar. }\end{array}$ \\
\hline & Exhibition Space & Pameran, Presentasi/ promosi bisnis \\
\hline & Photo Studio & Memotret produk model, Shoot video \\
\hline & Idea Room & $\begin{array}{l}\text { Berdikusi dengan rekan kerja, } \\
\text { Menggambar ide/ konsep proyek }\end{array}$ \\
\hline & Phone Booth & Melakukan panggilan suara/ video \\
\hline & Print Room & Mencetak dokumen, Membeli ATK \\
\hline \multirow{4}{*}{$\begin{array}{l}\text { Refreshing } \\
\text { Area }\end{array}$} & Lounge & $\begin{array}{l}\text { Beristirahat santai Minum kopi/ teh, } \\
\text { Mendorong komunikasi }\end{array}$ \\
\hline & Play Area & $\begin{array}{l}\text { Bermain, Melepaskan rasa jenuh, } \\
\text { Mendorong komunikasi }\end{array}$ \\
\hline & Pantry \& Minibar & $\begin{array}{l}\text { Menyiapkan makanan/minuman, } \\
\text { Mencuci peralatan, Makan/ Minum, } \\
\text { Mendorong komunikasi }\end{array}$ \\
\hline & Smoke Room & Merokok, Mendorong komunikasi \\
\hline \multirow{5}{*}{ Service } & Receptionist & Informasi, Registrasi \\
\hline & Waiting Area & Menunggu, Bertemu tamu \\
\hline & Locker & Menyimpan barang/tas \\
\hline & Storage & $\begin{array}{l}\text { Menyimpan peralatan auditorium/ } \\
\text { private office yang sedang tidak } \\
\text { digunakan }\end{array}$ \\
\hline & Preparation Room & Ruang persiapan untuk speaker \\
\hline Staff Space & Staff Room & $\begin{array}{l}\text { Kegiatan administratif, mengontrol } \\
\text { kegiatan, staff istirahat }\end{array}$ \\
\hline
\end{tabular}

Sumber: Analisis Penulis (2020)

\section{B. Persyaratan Umum Ruang dalam Fasilitas Co-Working Space}

Dalam merancang sebuah co-working space harus menyesuaikan kebutuhan pengguna dan menerapkan unsur tersebut ke dalam desain. Berikut ini dijabarkan mengenai kesimpulan 
standarisasi yang didapat dari data primer atau sekunder yang terkait dan menjadi acuan dalam mendesain perancangan Point Lab Co-Working Space ini:

Tabel 2. Kesimpulan Persyaratan Ruang dalam Co-Working Space

\begin{tabular}{|c|c|c|}
\hline Ruang & Persyaratan Umum Ruang & Sumber \& Keterangan \\
\hline $\begin{array}{c}\text { Individu } \\
\text { Workspace }\end{array}$ & $\begin{array}{l}\text { a. Lokasi: Berada di area yang tingkat } \\
\text { kebisingannya rendah } \\
\text { b. Layout: Area kerja individu tetap } \\
\text { berintergrasi dengan area co-working, } \\
\text { Tidak memberi rasa terisolasi sendiri } \\
\text { c. Fasilitas: Furniture seperti meja kerja } \\
\text { (minimal } 180 \times 80 \mathrm{~cm} \text { ), kursi, unit laci } \\
\text { dan beberapa rak; Terdapat layanan } \\
\text { listrik, telepon dan data, serta teknologi } \\
\text { WiFi. } \\
\text { d. Kenyamanan optimal dalam } \\
\text { pencahayaan, pengkondisian udara dan } \\
\text { akustik (Standar SNI-03-6197- } \\
\text { e. Pencahayaan } \\
\text { 2000): 350 Lux }\end{array}$ & $\begin{array}{c}\text { Diputacio de Barcelona, } \\
2014 \text {, hal. } 113\end{array}$ \\
\hline $\begin{array}{c}\text { Co-Working } \\
\text { Area }\end{array}$ & $\begin{array}{l}\text { a. Lokasi: Dekat dengan area resepsionis } \\
\text { b. Layout: Menyediakan ruang yang } \\
\text { menawarkan konektivitas dan ruang } \\
\text { kerja yang menawarkan tingkat } \\
\text { keintiman atau konsentrasi tertentu, } \\
\text { Modul kerja menghadap area sirkulasi } \\
\text { dan ruang komunal. } \\
\text { c. Fasilitas: Tiap modul area kerja untuk 4- } \\
8 \text { individu; Furniture dengan fleksibilitas } \\
\text { tinggi seperti meja kerja (minimal } \\
\text { 180x80 cm tiap individu), kursi dengan } \\
\text { roda, laci yang dapat dikunci, saluran } \\
\text { kabel, stop kontak dan akses WiFi; } \\
\text { Terdapat layanan komputer/ telepon } \\
\text { bersama; Terdapat Concentration Box/ } \\
\text { Kubikal dengan luas permukaan sekitar } \\
8 \text { m }{ }^{2}-10 \text { m² } \\
\text { d. Menerapkan akustik/ penyerap suara } \\
\text { pada dinding, langit-langit atau } \\
\text { furniture. } \\
\text { e. Mendapat akses sinar matahari dan } \\
\text { ventilasi alami } \\
\text { f. Menggunakan warna terang agar ruang } \\
\text { terkesan luas, dapat memantulkan } \\
\text { cahaya; Warna gelap ruang lebih intim } \\
\text { dan maskulin; Warna hangat memberi } \\
\text { visual kehangatan; Warna dingin } \\
\text { menyegarkan dan mengurangi rasa jenuh }\end{array}$ & $\begin{array}{l}\text {-Diputacio de Barcelona, } \\
\text {-Studi banding BDV } \\
\text { Meja untuk } 6 \text { orang lebih } \\
\text { privasi, dilengkapi led tv } \\
\text { sebagai fasilitas untuk } \\
\text { meeting secara informal } \\
\text { atau mendiskusikan ide/ } \\
\text { konsep. }\end{array}$ \\
\hline
\end{tabular}




\begin{tabular}{|c|c|c|}
\hline \multirow[t]{2}{*}{ Ruang } & Persyaratan Umum Ruang & Sumber \& Keterangan \\
\hline & $\begin{array}{l}\text { g. Pencahayaan (Standar SNI-03-6197- } \\
\text { 2000): } 350 \text { Lux }\end{array}$ & $\begin{array}{c}\text {-Studi banding GoWork } \\
\text { Menara Rajawali Jakarta. } \\
\text { Variasi area kerja quiet } \\
\text { area untuk co-worker } \\
\text { yang membutuhkan } \\
\text { ruang kerja dengan } \\
\text { kebisingan rendah. Area } \\
\text { kerja group workspace } \\
\text { untuk pengguna yang } \\
\text { datang secara } \\
\text { berkelompok. } \\
\text { Tiap area private office } \\
\text { mendapat pencahayaan } \\
\text { alami. }\end{array}$ \\
\hline Meeting Room & 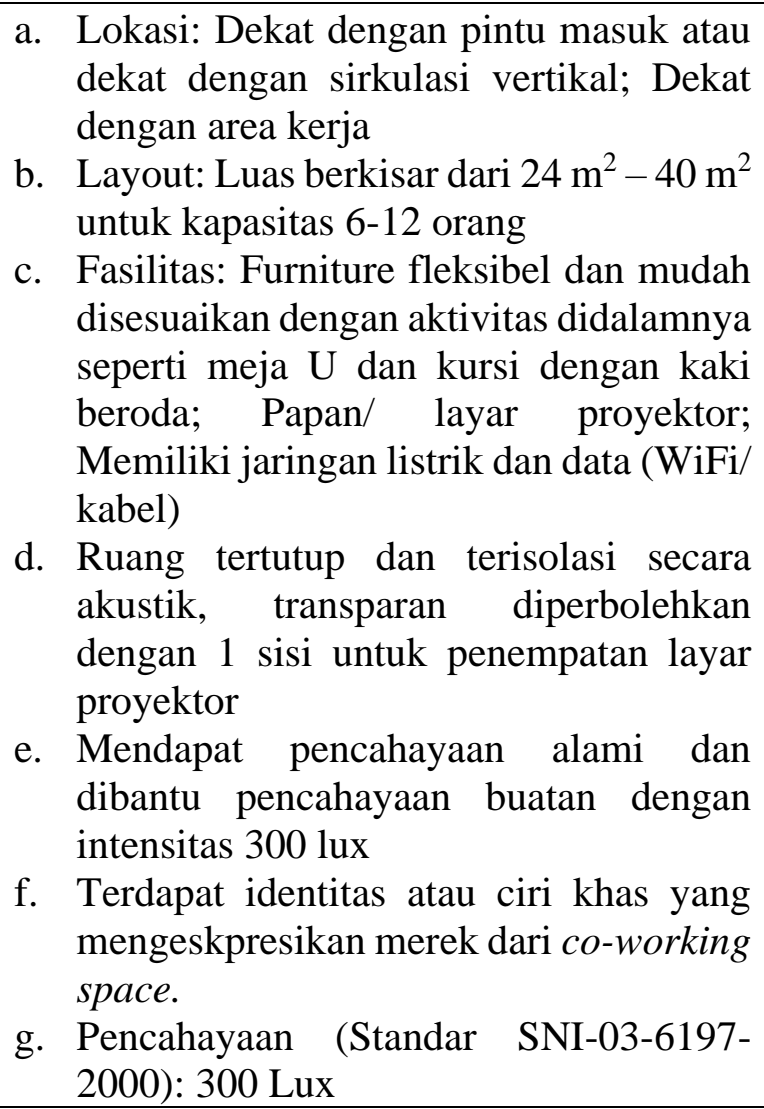 & $\begin{array}{l}\text {-Diputacio de Barcelona, } \\
\text { 2014, hal. } 123 \\
\text {-Studi banding BDV, } \\
\text { memberikan jarak privasi } \\
\text { antar penggunanya, } \\
\text { dengan fasilitas layar led } \\
\text { tv untuk memberi } \\
\text { kepraktisan dalam } \\
\text { mempresentasikan materi } \\
\text { rapat. }\end{array}$ \\
\hline $\begin{array}{c}\text { Informal } \\
\text { Meeting Area }\end{array}$ & $\begin{array}{l}\text { a. Lokasi: Penempatan bisa di indoor } \\
\text { ataupun outdoor yang mudah diakses; } \\
\text { Variasi penempatan di beberapa lokasi } \\
\text { terkait } \\
\text { b. Layout: Luas permukaan } 7 \mathrm{~m}^{2}-9 \mathrm{~m}^{2} \text {; } \\
\text { Dapat dibuat terbuka dan terintegrasi } \\
\text { dengan ruang sirkulasi umum, namun } \\
\text { ada batasan privasi orang didalamnya } \\
\text { c. Fasilitas: Furniture yang menarik, }\end{array}$ & $\begin{array}{l}\text { Diputacio de Barcelona, } \\
\text { 2014, hal. } 122\end{array}$ \\
\hline
\end{tabular}


Vol. 5, No. 2, Desember 2020, pISSN 2527-2853, eISSN 2549-2985

\begin{tabular}{|c|c|c|}
\hline \multirow[t]{2}{*}{ Ruang } & Persyaratan Umum Ruang & Sumber \& Keterangan \\
\hline & $\begin{array}{l}\text { nyaman dan informal seperti kursi } \\
\text { berlengan } \\
\text { d. Pencahayaan cukup terang sebagai area } \\
\text { yang menyenangkan }\end{array}$ & \\
\hline Auditorium & 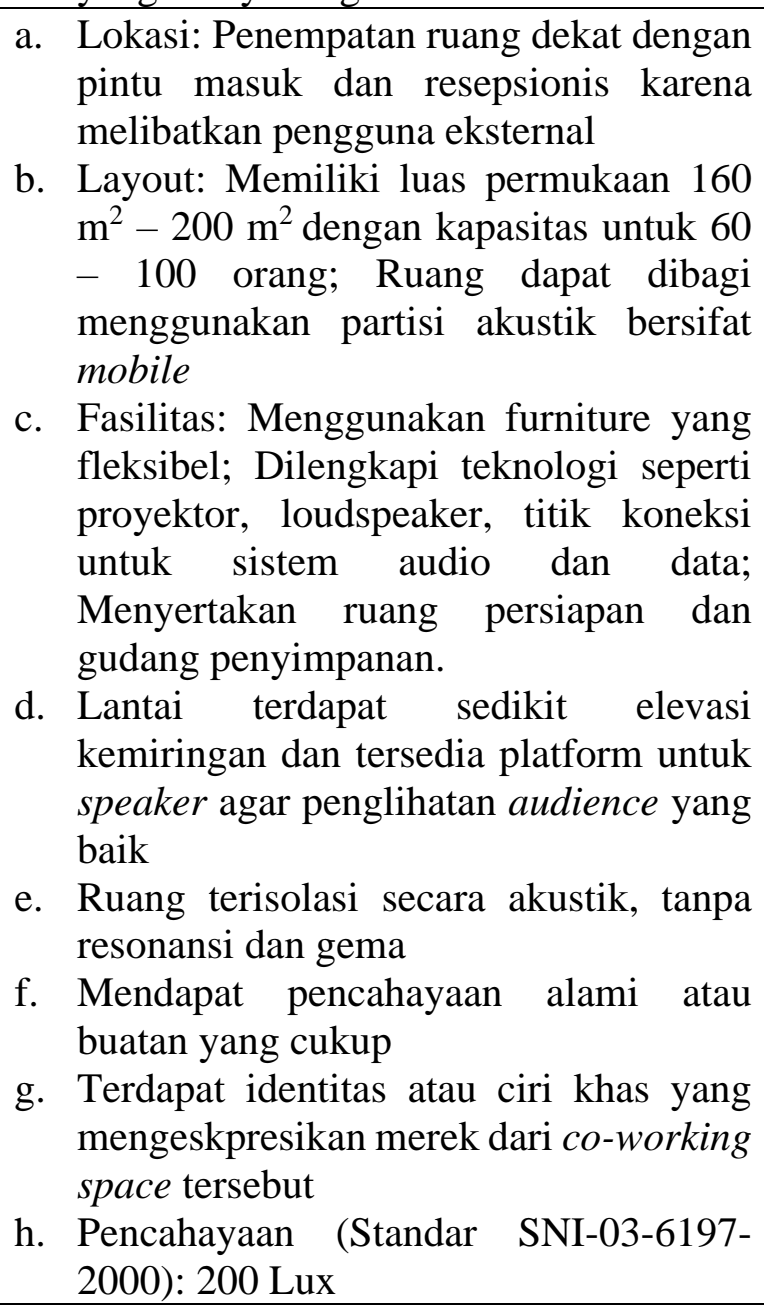 & $\begin{array}{l}\text {-Diputacio de Barcelona, } \\
\text { 2014, hal.126 } \\
\text { Furniture loose fleksibel, } \\
\text { terdapat meja lipat pada } \\
\text { kursinya.hal ini } \\
\text { memudahkan user untuk } \\
\text { mencatat materi. } \\
\text { Material menggunakan } \\
\text { tekstur kayu dan } \\
\text { dipadukan dengan warna } \\
\text { putih memberi ruang } \\
\text { yang terkesan muda dan } \\
\text { luas. }\end{array}$ \\
\hline Relax Area & $\begin{array}{l}\text { a. Lokasi: Area yang mudah diakses dan } \\
\text { dikenali, tidak terpisah dari area } \\
\text { sirkulasi, terkonsentrasi di satu tempat } \\
\text { b. Layout: Memiliki luas permukaan } 30 \mathrm{~m}^{2} \\
-36 \mathrm{~m}^{2} \text {; Ruang tidak sepenuhnya } \\
\text { tertutup agar tidak mengurangi interaksi } \\
\text { pengguna } \\
\text { c. Fasilitas: Furniture kasual dan nyaman } \\
\text { seperti meja rendah, kursi berlengan dan } \\
\text { sebagainya; Dapat dilengkapi dengan } \\
\text { perpustakaan atau bookshare } \\
\text { d. Suasana ruang yang mendukung orang } \\
\text { untuk rileks, seperti penggunaan warna } \\
\text { hijau, biru } \\
\text { e. Mendapat pencahayaan alami dan } \\
\text { pendingin udara yang nyaman }\end{array}$ & $\begin{array}{l}\text { Diputacio de Barcelona, } \\
\text { 2014, hal.130 }\end{array}$ \\
\hline
\end{tabular}




\begin{tabular}{|c|c|c|}
\hline Ruang & Persyaratan Umum Ruang & Sumber \& Keterangan \\
\hline & $\begin{array}{l}\text { f. Pencahayaan (Standar SNI-03-6197- } \\
\text { 2000): 250 Lux }\end{array}$ & \\
\hline Play Area & $\begin{array}{l}\text { a. Lokasi: Dekat dengan pantry dan } \\
\text { lokasinya mudah di akses } \\
\text { b. Layout: Luas permukaan } 30 \mathrm{~m}^{2}-36 \mathrm{~m}^{2} \text {; } \\
\text { c. Fasilitas: Didukung permainan yang } \\
\text { menghasilkan kejuaraan seperti } \\
\text { pingpong, meja sepak bola, anak panah, } \\
\text { meja billiard dan sebagainya; Furniture } \\
\text { yang informal, suasana yang dihadirkan } \\
\text { menyenangkan dengan dinamis dan } \\
\text { muda. } \\
\text { d. Ruang diisolasi secara akustik karena } \\
\text { bisa menghasilkan kebisingan } \\
\text { e. Memiliki cahaya alami, ventilasi dan } \\
\text { pendingin udara (terutama jika ada } \\
\text { aktivitas aerobik) } \\
\text { f. Pencahayaan (Standar SNI-03-6197- } \\
\text { 2000) : 200 Lux }\end{array}$ & $\begin{array}{l}\text {-Diputacio de Barcelona, } \\
2014, \text { hal.134 } \\
\text {-Studi banding GoWork, } \\
\text { menempatkan area } \\
\text { bermain menyatu dengan } \\
\text { lounge sebagai area } \\
\text { istirahat untuk } \\
\text { menciptakan nilai } \\
\text { komunitas }\end{array}$ \\
\hline Pantry & $\begin{array}{l}\text { a. Lokasi: Mudah di akses \& dekat } \\
\text { relax/play space } \\
\text { b. Layout: Luas permukaan } 60 \mathrm{~m}^{2}-100 \\
\mathrm{~m}^{2} \text {; Ruang terbuka terhadap sirkulasi } \\
\text { c. Fasilitas: Meja kerja panjang untuk } \\
\text { mendorong komunikasi; Lengkap } \\
\text { dengan counter dapur panjang, untuk } \\
\text { wastafel microwave, lemari es, mesin } \\
\text { kopi dan lainnya } \\
\text { d. Mendapat banyak pencahayaan alami } \\
\text { e. Pencahayaan (Standar SNI-03-6197- } \\
\text { 2000) : 250 Lux }\end{array}$ & $\begin{array}{l}\text {-Diputacio de Barcelona, } \\
\text {-Studi banding GoWork, } \\
\text { menempatkan pantry } \\
\text { dekat dengan area } \\
\text { istirahat dan bermain } \\
\text {-Studi banding BDV, } \\
\text { memfasilitasi dengan } \\
\text { meja bar panjang untuk } \\
\text { menciptakan komunikasi } \\
\text { antar user ketika mereka } \\
\text { beristirahat dari } \\
\text { pekerjaan. }\end{array}$ \\
\hline $\begin{array}{l}\text { Sirculation } \\
\quad \text { Area }\end{array}$ & $\begin{array}{l}\text { a. Lebar koridor penghubung ruang } \\
\text { minimal } 180 \mathrm{~cm} \\
\text { b. Lebar sirkulasi ideal antar modul kerja di } \\
\text { area coworking space minimal } 120 \mathrm{~cm}- \\
150 \mathrm{~cm} \text {. } \\
\text { c. Jalur sirkulasi harus jelas, karena }\end{array}$ & $\begin{array}{c}\text { Diputacio de Barcelona, } \\
2014 \text {, hal.129 }\end{array}$ \\
\hline
\end{tabular}


Vol. 5, No. 2, Desember 2020, pISSN 2527-2853, eISSN 2549-2985

\begin{tabular}{|c|c|c|}
\hline Ruang & $\begin{array}{l}\text { Persyaratan Umum Ruang } \\
\text { menerima kunjungan eksternal } \\
\text { d. Pencahayaan (Standar SNI-03-6197- } \\
\text { 2000): 100 Lux }\end{array}$ & Sumber \& Keterangan \\
\hline $\begin{array}{c}\text { Lobby \& } \\
\text { Receptionist }\end{array}$ & $\begin{array}{l}\text { a. Lokasi: Penempatan berada di area } \\
\text { publik pintu masuk utama } \\
\text { b. Layout: Area resepsionis dan ruang } \\
\text { tunggu berada di depan pintu masuk } \\
\text { c. Fasilitas: Terdapat meja dan kursi di area } \\
\text { resepsionis; Pada ruang tunggu terdapat } \\
\text { sofa yang nyaman dengan backrest dan } \\
\text { meja kecil } \\
\text { d. Menampilkan identitas/ ciri khas merek } \\
\text { dari co-working space } \\
\text { e. Mendapat pencahayaan alami } \\
\text { f. Pencahayaan (Standar SNI-03-6197- } \\
\text { 2000): 300 Lux }\end{array}$ & $\begin{array}{l}\text {-How to Create a } \\
\text { Coworking Space, } 2013 \\
\text {-Studi banding BDV \& } \\
\text { CoHive, resepsionis } \\
\text { berada di depan pintu } \\
\text { masuk dan terdapat area } \\
\text { tunggu serta mendapat } \\
\text { pencahayaan alami } \\
\text { membuat suasana ruang } \\
\text { lebih fresh. }\end{array}$ \\
\hline $\begin{array}{l}\text { Rephrograpics } \\
\text { Area/ Print } \\
\text { Room }\end{array}$ & $\begin{array}{l}\text { a. Lokasi: Penempatan dekat dengan } \\
\text { modul/area kerja } \\
\text { b. Layout: Memiliki luas permukaan } 9 \mathrm{~m}^{2}- \\
15 \mathrm{~m}^{2} \\
\text { c. Fasilitas: Perlengkapan mesin fotokopi, } \\
\text { printer, jilid, meja kerja dan kursi } \\
\text { d. Sebaiknya ruang terisolasi secara akustik } \\
\text { untuk mengurangi dampak bising dari } \\
\text { suara mesin } \\
\text { e. Pencahayaan (Standar SNI-03-6197- } \\
\text { 2000): 300 Lux }\end{array}$ & $\begin{array}{c}\text { Diputacio de Barcelona, } \\
\text { 2014, hal. } 137\end{array}$ \\
\hline Storage Room & $\begin{array}{l}\text { a. Lokasi: Penempatan ruang ditempatkan } \\
\text { di bagian dalam, tidak perlu dekat } \\
\text { dengan modul kerja dan dapat } \\
\text { menampung barang-barang office tenant } \\
\text { di co-working space } \\
\text { b. Fasilitas: Dapat berupa loker, atau lemari } \\
\text { untuk penyimpanan barang member/ } \\
\text { daily user co-working } \\
\text { c. Pencahayaan (Standar SNI-03-6197- } \\
\text { 2000): } 150 \text { Lux }\end{array}$ & $\begin{array}{c}\text { Diputacio de Barcelona, } \\
2014 \text {, hal. } 119\end{array}$ \\
\hline $\begin{array}{l}\text { Computer } \\
\text { Room }\end{array}$ & $\begin{array}{l}\text { a. Lokasi: Dekat dengan modul kerja, } \\
\text { mudah di akses } \\
\text { b. Layout: Standar } 4 \mathrm{~m}^{2} \text { per individu; }\end{array}$ & $\begin{array}{c}\text { PERMENRISTEKDIKTI } \\
\text { No.51, } 2018\end{array}$ \\
\hline
\end{tabular}




\begin{tabular}{|c|c|c|}
\hline Ruang & Persyaratan Umum Ruang & Sumber \& Keterangan \\
\hline & $\begin{array}{l}\text { Maksimal } 20 \text { orang dalam satu ruangan } \\
\text { c. Fasilitas: Furniture meja komputer, kursi } \\
\text { kerja dengan mobilitas tinggi, layar atau } \\
\text { papan proyektor; Memiliki koneksi } \\
\text { jaringan listrik, LAN dan Wifi } \\
\text { d. Mendapat pencahayaan alami agar } \\
\text { warna pada layar komputer tidak } \\
\text { berubah } \\
\text { e. Memiliki pengkondisian udara (AC); } \\
\text { Suhu stabil temperatur ruang } 20^{\circ} \mathrm{C}-24^{\circ} \mathrm{C} \\
\text { dan kelembapan relatif } 45 \%-55 \% \\
\text { f. Ruangan memiliki akustik yang baik } \\
\text { agar suara tidak menggema } \\
\text { g. Pencahayaan (Standar SNI-03-6197- } \\
\text { 2000): 350 Lux }\end{array}$ & \\
\hline Photo Studio & $\begin{array}{l}\text { a. Lokasi: Dekat dengan workspace } \\
\text { b. Layout: Menyesuaikan dengan dimensi } \\
\text { ruang dan kapasitas jumlah pengguna } \\
\text { c. Fasilitas: Menggunakan furniture dan } \\
\text { peralatan foto dengan mobilitas tinggi } \\
\text { seperti sistem loose dan mobile agar } \\
\text { dapat dipindahkan } \\
\text { d. Elemen dinding lantai serta plafon } \\
\text { simple dengan warna monokrom dan } \\
\text { material yang dapat menyerap cahaya, } \\
\text { tidak menimbulkan bayangan dan efek } \\
\text { pantul. Disarankan mendapat } \\
\text { pencahayaan alami } \\
\text { e. Pencahayaan (Standar SNI-03-6197- } \\
\text { 2000): 500 Lux }\end{array}$ & $\begin{array}{l}\text {-Panduan Teknis Foto, } \\
\text { Bab III, Griand Giwanda; } \\
\text { Perpustakaan Nasional } \\
\text { RI, } 2011 \\
\text {-Studi banding GoWork, } \\
\text { terdapat photo studio } \\
\text { sebagai fasilitas untuk } \\
\text { tenant memoto } \\
\text { produknya. }\end{array}$ \\
\hline $\begin{array}{l}\text { Exhibition } \\
\text { Space }\end{array}$ & $\begin{array}{l}\text { a. Lokasi: Dekat dengan lobby dan } \\
\text { resepsionis sehingga mudah diakses oleh } \\
\text { publik } \\
\text { b. Layout: Menggunakan metode } \\
\text { penyajian interaktif dengan teknologi, } \\
\text { agar pengunjung dapat berinteraksi } \\
\text { langsung dengan produk/ jasa yang } \\
\text { ditawarkan; Dengan menggunakan alur } \\
\text { yang disarankan/ suggested } \\
\text { c. Fasilitas: Terdapat platform dan panel } \\
\text { untuk menyajikan produk yang } \\
\text { dipamerkan sesuai dengan tinggi } \\
\text { manusia indonesia rata-rata } 160 \mathrm{~cm}-170 \\
\text { cm, lemari tebal } 80 \mathrm{~cm} \text { dan tinggi } 160 \mathrm{~cm} \\
\text { d. Menggunakan warna pada ruang yang } \\
\text { netral agar dapat menyesuaikan dengan } \\
\text { produk yang sedang dipamerkan }\end{array}$ & $\begin{array}{c}\text {-Pedoman Tata Pameran, } \\
\text { Departemen Pendidikan } \\
\text { dan Kebudayaan } \\
\text { Permuseuman Jakarta, } \\
\text { 1997) } \\
\text {-Studi Banding BDV, } \\
\text { terdapat Display Room } \\
\text { untuk media promosi } \\
\text { tenant startup, hal ini } \\
\text { juga dapat memperluas } \\
\text { relasi. }\end{array}$ \\
\hline
\end{tabular}


Vol. 5, No. 2, Desember 2020, pISSN 2527-2853, eISSN 2549-2985

\begin{tabular}{|l|l|l|}
\hline Ruang & \multicolumn{1}{|c|}{ Persyaratan Umum Ruang } & Sumber \& Keterangan \\
\hline & e. Jika menggunakan pencahayaan buatan & \\
& gunakan jenis lampu indirect agar tidak & \\
& mengganggu benda yang dipamerkan & \\
& dan menyilaukan pengunjung. & \\
& f. $\begin{array}{l}\text { Pencahayaan (Standar SNI-03-6197- } \\
\text { 2000): 300 Lux }\end{array}$ & \\
\hline
\end{tabular}

Sumber: Analisis Penulis (2020)

\section{Psikologi Ruang dengan Karakteristik Milenial}

Sasaran utama pengguna PointLab Co-Working Space merupakan generasi milenial. Berdasarkan sumber yang merupakan pendapat beberapa peneliti dan Generation Theory yang dicetuskan oleh (Karl Manheim, 1923) Generasi milenial atau generasi Y adalah populasi yang lahir antara tahun 1980 sampai 2000. Menurut Gallup (2016) yang dijelaskan dalam buku Statistik Gender Tematik Profil Generasi Milenial (2018) dalam aspek bekerja para milenial memiliki karakteristik yang jauh berbeda dengan generasi-generasi sebelumnya. Pendekatan psikologi ruang yang memasukan unsur karakteristik milennial kedalam ruang, diharapkan dapat mempengaruhi pengguna untuk meningkatkan potensi dari para milenial dan dapat mencapai tujuan dari perancangan sebuah co-working space sesungguhnya yang memiliki nilai komunitas, aksesibilitas, kolaborasi, komunikasi, keterbukaan dan kreativitas. Penerapan desain interior co-working space berdasarkan hal tersebut dijelaskan dalam tabel berikut:

Tabel 3. Penerapan Desain Berdasarkan Karakteristik Milenial

\begin{tabular}{|c|c|}
\hline Karakteristik Milenial & Penerapan Desain \\
\hline $\begin{array}{l}\text { - } \text { Memiliki komunikasi yang terbuka } \\
\text { - } \quad \text { Senang mengenal orang baru } \\
\text { seaktif terhadap perubahan lingkungan di } \\
\text { sekitarna }\end{array}$ & $\begin{array}{l}\text { Ruang dengan konsep yang terbuka/ } \\
\text { transparan dan saling terhubung, namun } \\
\text { tetap memberi privasi penggunanya }\end{array}$ \\
\hline $\begin{array}{l}\text { - Mementingkan self } \\
\text { pengembangan diri dari passion yang } \\
\text { dimilikinya } \\
\text { - } \begin{array}{l}\text { Menjadikan pendidikan sebagai prioritas } \\
\text { utama }\end{array}\end{array}$ & $\begin{array}{l}\text { Ruang pelatihan dengan fasilitas } \\
\text { pendukung dan program pelatihan }\end{array}$ \\
\hline $\begin{array}{l}\text { - Technology Savvy/ ahli dalam teknologi dan } \\
\text { melibatkannya kedalam aspek kehidupan } \\
\text { - Lebih produkitf dan efisien dengan bantuan } \\
\text { teknologi } \\
\text { - Inovatif dan Kreatif }\end{array}$ & $\begin{array}{l}\text { Menyediakan media teknologi ke dalam } \\
\text { peralatan untuk mendukung pekerjaan di } \\
\text { co-working space }\end{array}$ \\
\hline $\begin{array}{l}\text { - Mudah berpindah pekerjaan dalam waktu } \\
\text { singkat } \\
\text { - Menyenangi pekerjaan yang fleksibel } \\
\text { - Ingin serba cepat }\end{array}$ & $\begin{array}{l}\text { Variasi furniture dan lokasi area kerja } \\
\text { Warna utama ruang kerja yang memberi } \\
\text { tingkat fokus tinggi \& warna aksen untuk } \\
\text { memberikan psikologi kreatif, semangat, } \\
\text { menyenangkan dan menghubungkan } \\
\text { penggunanya } \\
\text { Menerapkan furniture dengan mobilitas } \\
\text { tinggi }\end{array}$ \\
\hline
\end{tabular}




\begin{tabular}{|c|l|}
\hline Karakteristik Milenial & \multicolumn{1}{c|}{ Penerapan Desain } \\
\hline Mementingkan Work-Life-Balance & $\begin{array}{l}\text { Ruang sosial yang terpusat pada satu area, } \\
\text { sehingga dapat mengumpulkan pengguna } \\
\text { ketika mereka beristirahat dari pekerjaan } \\
\text { individunya. }\end{array}$ \\
\hline
\end{tabular}

Sumber: Analisis Penulis (2020)

\section{Organisasi Ruang Terpusat pada Social Space}

Menyesuaikan dengan tujuan dan konsep perancangan To-Get-There yang bermaksud untuk menyatukan para user Point Lab, maka pada perancangan ini menggunakan bentuk organisasi ruang terpusat yang berfungsi untuk menghubungkan penggunanya. Sebuah ruang yang menjadi pusat dari pengelompokan sejumlah ruang lainnya. Organisasi terpusat bisa dengan bentuk persegi atau radial. Ruang terpusat memiliki nilai penting yang bisa mengikat semua massa di sekitarnya.

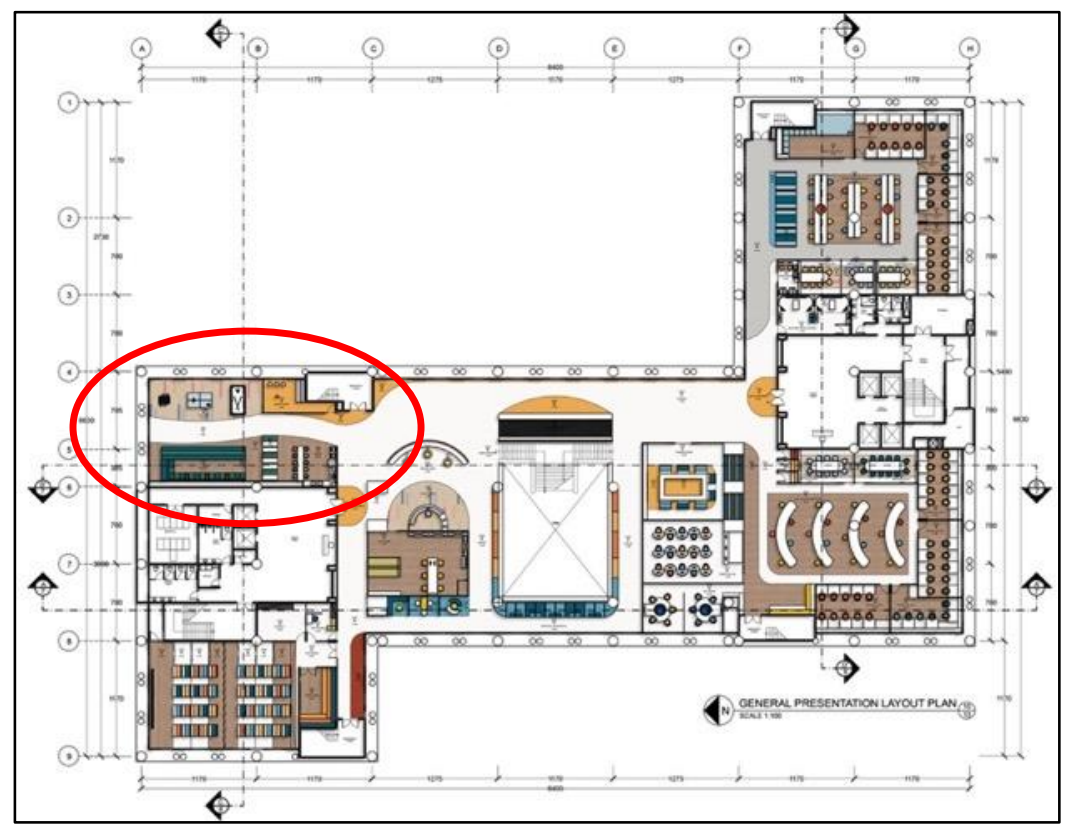

Gambar 2. Penerapan Organisasi Ruang Terpusat dalam Layout Objek Perancangan Sumber: Karya Penulis (2020)

Konsep organisasi ruang terpusat pada area refreshing yang merupakan ruang komunal atau social space yang digunakan untuk menghubungkan dan menyatukan pengguna untuk menciptakan nilai komunitas dan kolaborasi dalam lingkup ruang kerja bersama. Penerapan bentuk pada layout seperti pada pola lantai yang berusaha untuk mengarahkan user Point Lab Co-Working Space ke area refreshing atau ruang sosial disebelah utara bangunan eksisting.

\section{E. Gabungan Bentuk Dasar Geometri}

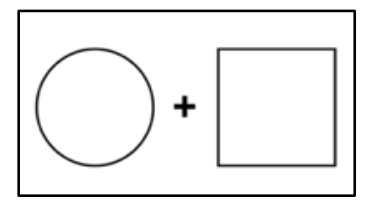

Gambar 3. Bentuk Kombinasi Geometri yang diaplikasikan dalam Perancangan Sumber: Dokumen Penulis (2020) 
Konsep bentuk yang diaplikasikan pada objek perancangan ini merupakan gabungan dari dua bentuk dasar geometri, yang bertujuan untuk mengutamakan nilai fungsi, sederhana namun tetap mengikuti perkembangan zaman.

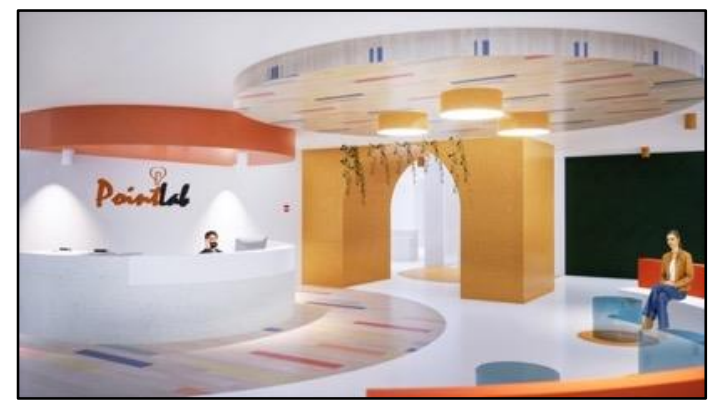

Gambar 4. Aplikasi Bentuk pada Elemen Ruang di Area Resepsionis Sumber: Karya Penulis (2020)

Penerapan bentuk geometri yang menghasilkan garis lengkung menciptakan kesan ruang dan karakteristik dari milenial yang menyukai suasana semi non-formal untuk sebuah lingkungan ruang kerja selain itu untuk memperhatikan keamanan pengguna.

\section{F. Pengaplikasian Warna}

Warna yang diterapkan merupakan warna untuk mendukung konsep dan suasana yang diharapkan, yaitu suasana ruang yang segar yang dapat meningkatkan kinerja penggunanya dalam bekerja ataupun berinteraksi sosial saat berada di co-working space ini.

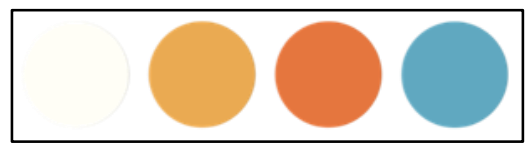

Gambar 5. Skema Warna yang Dominan digunakan pada Perancangan Sumber: Dokumen Penulis (2020)

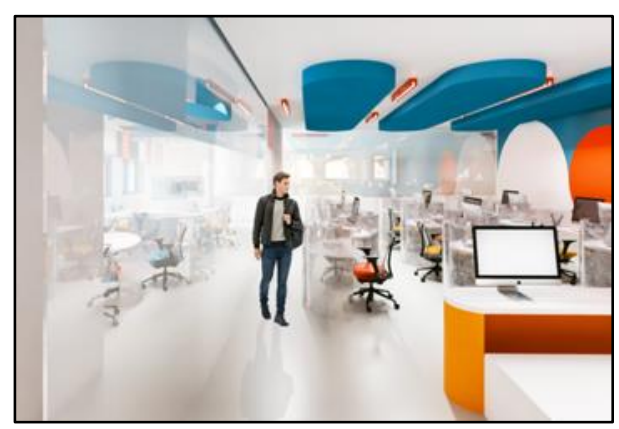

Gambar 6. Penerapan Warna Dominan pada Ruang Lab Komputer Sumber: Karya Penulis (2020)

Dilihat dari sisi psikologi, pemilihan warna yang diterapkan seperti warna putih sebagai warna dasar untuk memberi kesan ruang yang lebih segar, luas dan terbuka. Warna putih ini juga untuk menginterpretasikan teknologi yang berhubungan dengan startup digital tersebut. Selain itu terdapat warna aksen yang menggunakan warna biru dan tone kuning-oranye yang dapat mendukung utnuk meningkatkan kreativitas serta menghadirkan ruang kerja yang menyenangkan untuk milenial startup digital. Warna oranye ini juga memiliki kesan bersahabat dan merupakan warna identitas dari brand terkait yaitu PT. Pos Indonesia dan Point Lab Co- 
Working Space itu sendiri Untuk menetralkan suasana dingin dari warna dominan putih dan cerah ini juga diberikan warna hangat seperti coklat dari material kayu dan warna biru dan hijau tua.

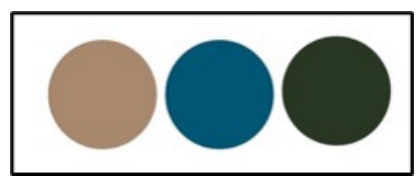

Gambar 7. Skema Warna Tambahan digunakan pada Perancangan Sumber: Dokumen Penulis (2020)

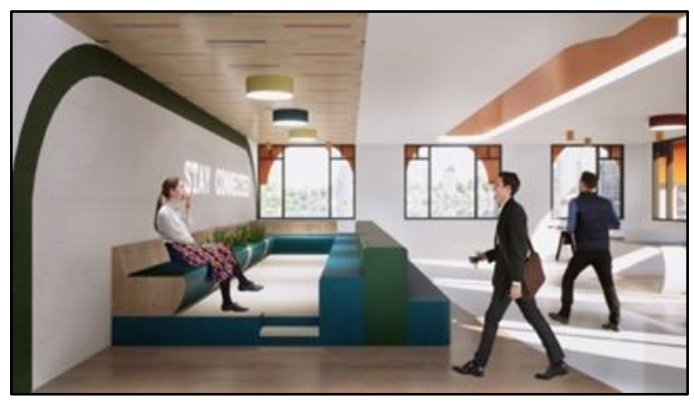

Gambar 8. Penerapan Konsep Warna Tambahan pada Area Lounge Sumber: Karya Penulis (2020)

\section{G. Kontribusi Minimalisir Sampah Material dalam Lingkungan}

Konsep material yang diterapkan adalah material yang dapat bertahan lama masa penggunaanya, sehingga dapat berkontribusi untuk mengurangi sampah material dalam lingkungan. Selain itu beberapa material untuk mendukung konsep To-Get-There dalam interior Point Lab Co-Working Space ini.

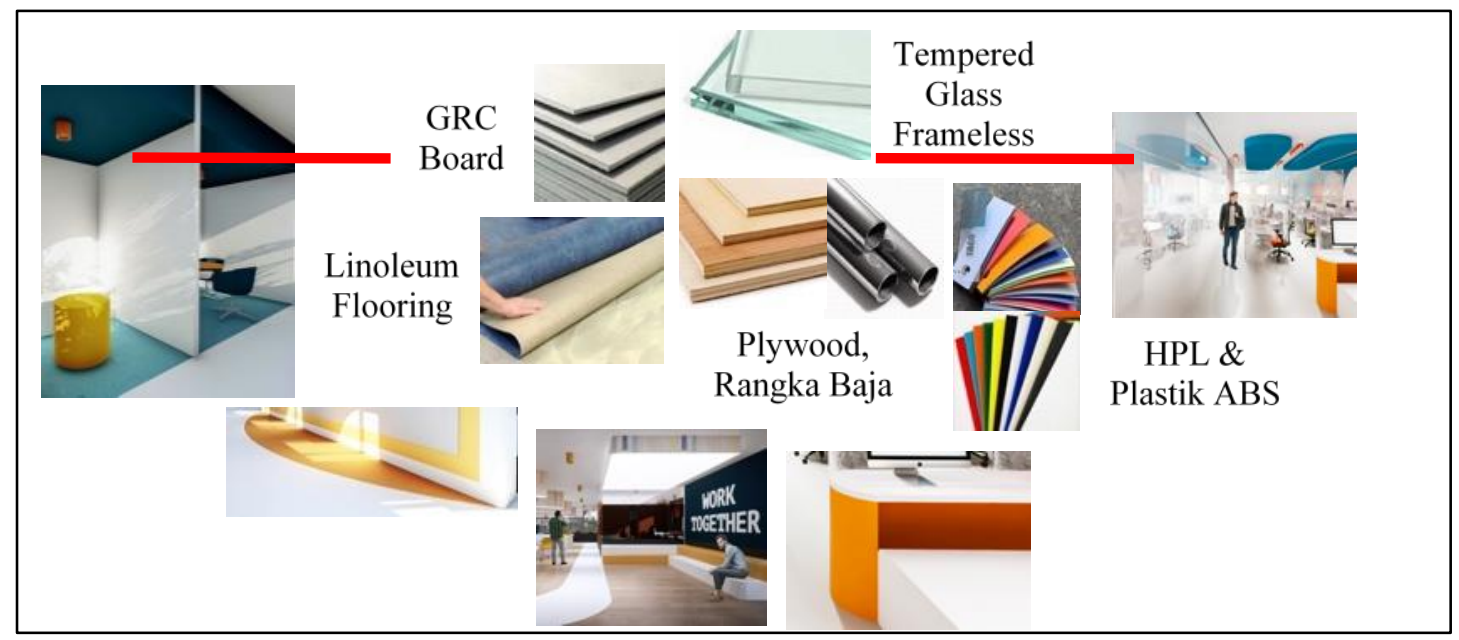

Gambar 9. Penerapan Material yang Digunakan Sumber: Dokumen Penulis (2020)

Penerapan material tersebut kedalam elemen ruang, seperti untuk dinding partisi menggunakan GRC Board yang juga digunakan untuk material penutup plafon dan partisi kaca frameless untuk mendukung konsep ruang terbuka namun tetap memiliki batasan privasi antar pengguna. Elemen lantai menggunakan lantai linoleum yang terbuat dari bahan alami, dan tahan panas serta mudah perawatannya. Untuk material furniture menggunakan rangka baja lebih kuat 
dan ditutup oleh papan plywood dengan finishing menggunakan HPL ataupun plastik ABS warna solid.

\section{H. Maksimalisasi Pencahayaan Alami}

Penerapan pencahayaan alami pada objek perancangan ini dimaksimalkan, untuk memanfaatkan kondisi bangunan eksisting yang dikelilingi jendela dan juga untuk menghemat energi listrik, baik untuk kesehatan penggunanya karena dapat membunuh kuman dalam ruang. Pencahayaan alami ini tidak terpapar langsung ke dalam ruang, karena pada bangunan eksisting terdapat kanopi di luar jendela.

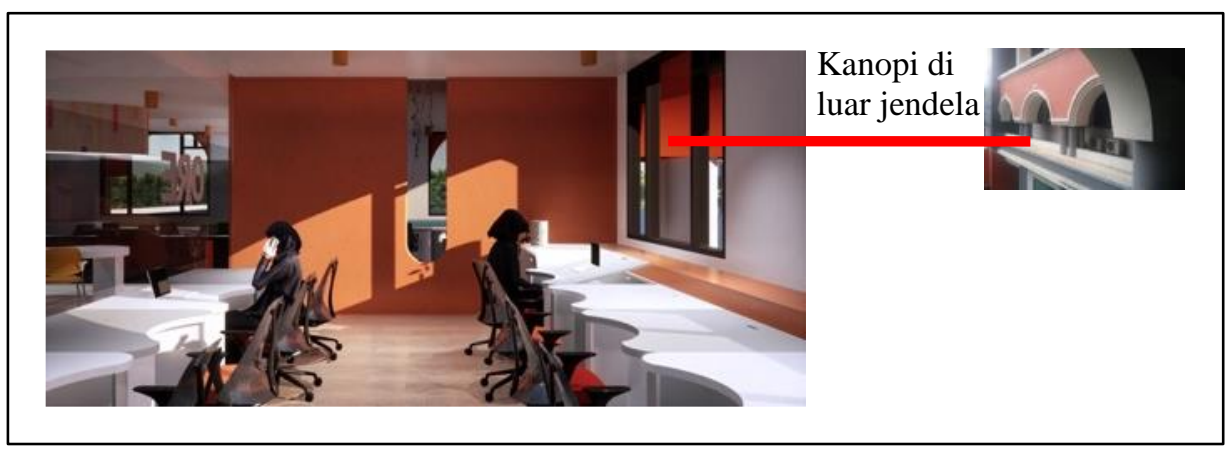

Gambar 10. Penerapan Maksimalisasi Pencahayaan Alami pada Ruang Private Office Sumber: Karya Penulis (2020)

Selain pencahayaan alami, pencahayaan buatan direncanakan berdasarkan kebutuhan cahaya ditiap ruang sesuai persyaratan dan standar dalam co-working space dengan mempertimbangkan efisiensi dan penghematan energi yang digunakan. Jenis pencahayaan General Task Lighting diterapkan melalui jenis lampu LED yang masa penggunaanya dapat bertahan lama. Penerapan jenis pencahayaan ini untuk memberikan pencahayaan tambahan pada area tertentu yang kurang mendapat pencahayaan alami secara maksimal, serta berperan sebagai pencahayaan umum pada co-working space tersebut.

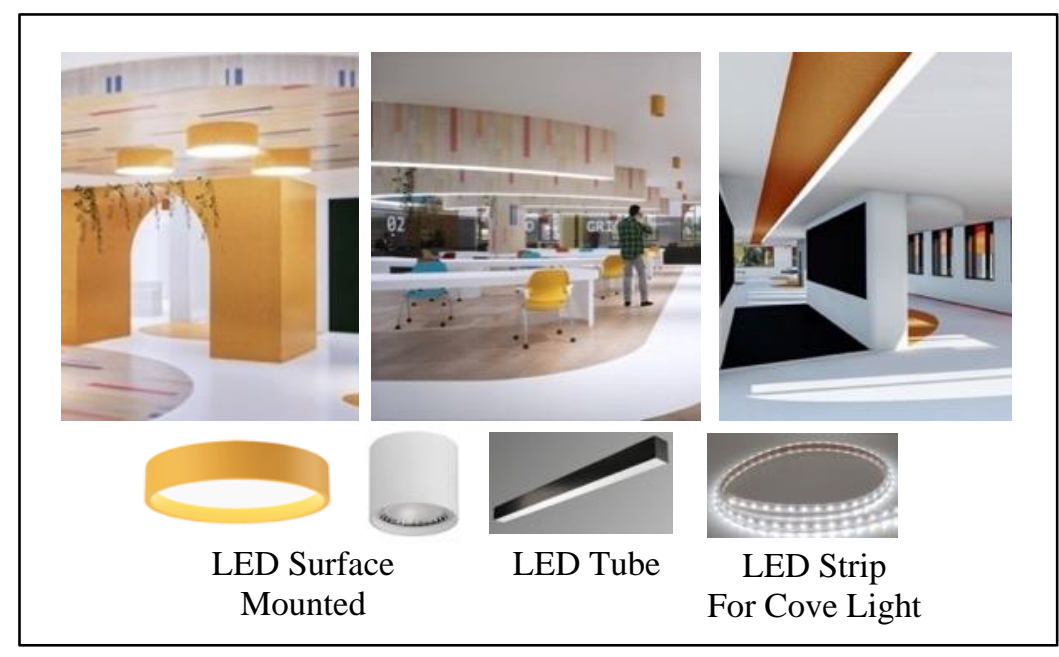

Gambar 11. Penerapan Pencahayaan Buatan pada Ruang di Co-Working Space Sumber: Karya Penulis (2020)

Warna cahaya pada pencahayaan buatan dibagi menjadi dua yaitu pada workspace menggunakan cahaya lampu warna daylight sesuai standar pencahayaan untuk aktivitas 
bekerja, dan cahaya lampu berwarna warm white untuk social space, agar suasana ruang lebih hangat.

\section{Fleksibilitas Pengguna pada Aplikasi Furniture}

Penerapan furniture dominan menggunakan loose furniture yaitu furniture yang dapat dipindah-pindahkan seperti meja kerja, kabinet pada private office. Terakhir mobile furniture yaitu furniture yang dapat berpindah dan memiliki roda untuk mempermudah pergerakan user contohnya terdapat di kursi kerja area co-working, private office, idea room dan meeting room. Sementara jenis built-in yaitu furniture yang dirancang menempel atau ditanam pada elemen ruang seperti dinding atau lantai contohnya bleachers, workpods dan sofa pada lounge, furniture bersifat built-in ini diterapkan sebagai pembatas area.

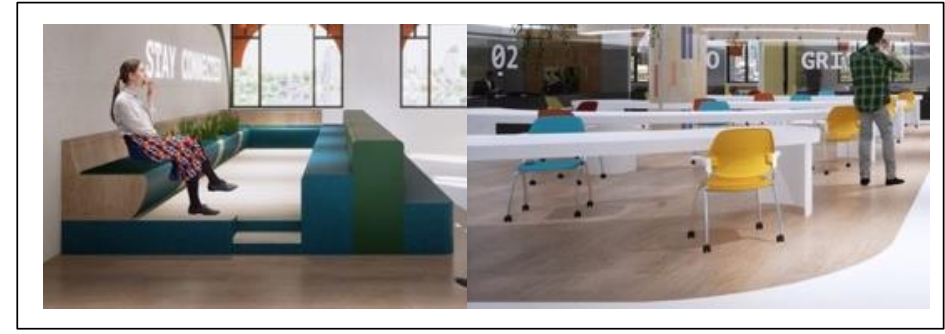

Gambar 12. Penerapan Furniture Loose, Mobile, dan Built-In pada Point Lab Co-Working Space Sumber: Karya Penulis (2020)

\section{KESIMPULAN}

Dalam co-working space terdapat co-worker atau pengguna yang memiliki maksud dan tujuan dalam menyewa sebuah ruang kerja bersama yaitu untuk membesarkan bisnis atau usaha mereka. Co-working space merupakan ruang kerja bersama yang memilki nilai komunitas, aksesibilitas, kolaborasi, komunikasi, keterbukaan dan kreativitas. Nilai-nilai tersebut menjelaskan bahwa dalam co-working space tidak hanya aktivitas bekerja saja melainkan kebutuhan penggunanya dalam berinteraksi sosial juga diutamakan, sehingga tercapai keseimbangan antara pekerjaan dan kehidupan sosialnya. Penerapan karakteristik pengguna dominan yang merupakan startup digital milenial kedalam interior Point Lab Co-Working Space ini diharapkan dapat meningkatkan antusias dan kinerja mereka dalam beraktivitas di coworking tersebut. Selain itu, pengorganisasian ruang berdasarkan konsep "To-Get-There” yang memusat atau mengarah ke area refreshing atau social space yang bertujuan untuk memberikan ruang yang memiliki nilai komunitas sehingga dapat menciptakan kolaborasi antar penggunanya Selain kebutuhan ruang dari pengguna dominan tersebut, pada perancangan ini juga memperhatikan pengguna lain yang biasanya merupakan pekerja lepas ataupun mahasiswa dari beberapa bidang pekerjaan lain. Dengan penerapan ide pada Point Lab Co-Working Space ini juga diharapkan dapat memenuhi tujuan dari PT. Pos Properti ataupun Point Lab itu sendiri dalam berkontribusi untuk pengembangan PT. Pos Indonesia.

\section{DAFTAR PUSTAKA}

Andreas D. Handoyo, Mahendra Nur Hadiansyah. (2017). "Pengaruh Desain Interior Kelas Tokong Nanas Terhadap Kenyamanan Visual Mahasiswa”. Jurnal Idealog. 2(1): 93-106

Barcelona, Diputacio De. (2014). Criteria for the Planning Programming, Design and Construction of Business Centres and Executive Suite, Coworking Space

Budiati. Indah, dkk. (2018). Statistik Gender Tematik Profil Generasi Milenial. Jakarta: Kementrian Pemberdayaan Perempuan dan Perlindungan Anak 
Dermot Egan. (2013). The Growth of Hybrid Coworking Space. Tersedia pada: http://www.deskmag.com/en/hybrid-coworking-space-design-the-hub-clubworkspacelondon-

697\#: :text=This\%20hybrid\%20coworking\%20model\%20reflects,their\%20team\%20si ze\%20as\%20required., diakses April 2020

Ella Delvianti. (2017). Re-Desain Co-Working Space Bandung Digital Valley [Skripsi]. Bandung (ID): Universitas Telkom Bandung

Ergin, Dugyu. (2013). How To Create a Coworking Space Handbook. Milan: Politecnico

Green Building Jakarta. Panduan Pengguna Bangunan Gedung Hijau Jakarta Berdasarkan Peraturan Gubernur No. 38/2012 Vol.3 Sistem Pencahayaan. Tersedia pada: https://greenbuilding.jakarta.go.id/files/userguides/IFCGuideVol3-IND.pdf, diakses Maret 2020

Hania Kasih. (2017). Perancangan Co-Working Space Sebagai Media Fasilitas Bidang Profesi Multimedia di Kota Bandung [Skripsi]. Bandung (ID): Universitas Telkom Bandung

Oxford. (2017). Definition of Co-Working Space in English. Tersedia pada: https://www.lexico.com/definition/co-working, diakses Januari 2020

Refyanti Dwi, Djoko Murdowo, Irwan Sudarisman, dan Andreas D. Handoyo. (2018). "Coworking Space Sebagai Solusi Kebutuhan Ruang Kerja Berdasarkan Karakteristik Startup Kreatif”. Jurnal Idealog. 3(1): 50-60

Refyanti Dwi. (2018). Perancangan Interior Creative Co-Working Space di Bandung [Skripsi]. Bandung (ID): Universitas Telkom Bandung

Remy Cagnol. (2013). The Hidden Treasures of Coworking. Tersedia pada: http://www.deskmag.com/en/coworking-library-studies-881/2, diakses April 2020

Robert Kropp. (2017). What Are The Basics of A Coworking Space. Tersedia pada: https://robertkropp.com/what-are-the-basics-of-a-coworking-space/, diakses Februari 2020

Schuermann, Mathias. (2014). Coworking Space A Potent Business Model for Plug ' $n$ Play and Indie Workers. E-Publi

Shafira Andriani, Djoko Murdowo, Rangga Firmansyah. (2018). "Analisis Desain Interior Kantor Call Center Telkomsel di Gedung Infomedia Nusantara Bandung dengan Pendekatan Psikologi Ruang”. Jurnal Idealog. 3(1): 61-74

Sholikhah, Laily dan Rullan Nirwansjah. (2018). "Penerapan Human-Centered Design dalam Perancangan Apartemen SOHO Biofilik sebagai Respon Pola Bekerja Era Bonus Demografi”. Jurnal Sains dan Seni ITS. 7(2)

Stumpf. (2013). Creativity \& Space Of BA In Coworking Spaces. Tersedia pada: https://www.zu.de/daily-wAssets/pdf/Masterarbeit_Stumpf_Daily.pdf, diakses Februari 2020

Yohanes Aldi. (2018). Perancangan Coworking Space Pendekatan Third Place pada Bangunan Lama di Kota Bandung [Tesis]. Bandung (ID): Institut Teknologi Bandung 
Adhiestyaputri Kintari, Mahendra Nur Hadiansyah, Widyanesti Liritantri

Penerapan Karakteristik Milenial sebagai Work-Life-Balance dalam Perancangan Fasilitas dan Elemen Interior

Point Lab Co-Working Space 